\title{
An Indigenously Developed Gate Driver Circuit for Three-Phase Smart Inverter Operated with Internet of Things
}

${ }^{1}$ Jithendri Accha, ${ }^{2}$ Devender Anthadpula, ${ }^{* 3}$ Ramsha Karampuri

${ }^{1,2,3}$ Centre for Emerging Energy Technologies, S R Engineering College, Warangal, Telangana, India. Email: ${ }^{1}$ jithendriaccha@gmail.com, ${ }^{2}$ anthadpula@gmail.com, ${ }^{3}$ ramsha.karampuri@gmail.com

Received: 06th October 2019, Accepted: 20th November 2019, Published: 31st December 2019

\begin{abstract}
In this paper, an attempt is made to introduce an indigenously made three-phase inverter feeding power to the three-phase induction motor. The developed three-phase inverter could be operated and controlled either manually using speed settings or by remotely using the Internet of Things (IoT). The proposed drive consists of three-phase inverter made of IGBTs and heat sinks, driver circuit designed using simple and low-cost ICs and other passive components, and the controller with Wi-Fi support. The detailed design of the drive system is presented in the paper. Also, the developed drive system is tested using a hardware prototype and the results are presented.
\end{abstract}

Keywords

Controller, Induction Motor, Internet of Things, Inverter, Pulse Width Modulation.

\section{Introduction}

Adjustable speed drives have occupied almost all the induction motor applications including industries, domestic, sea way transport, air way transport and the road way transport etc [1]-[2]. The speed control of an induction motor is achieved using the inverter connected to the stator of the motor. The power semiconductor devices of the inverter are controlled (turning ON and OFF) by a controller. However, the controller which works at lower power levels cannot be directly connected with the inverter switches. So, an intermediate circuit is required to isolate the low power controller with the high power inverter circuit [3]. Hence, often this intermediate circuit is termed as gate driver circuit, which is the most important part of an electrical drive system.

Many researchers have worked in designing and developing the gate driver circuits for various inverter topologies [4]-[8]. These include the gate drive circuits for insulated gate bipolar transistors with high power ratings used in various converter topologies like three-phase two-level inverter, neutral point clamped threelevel inverter, resonant converters etc.

Recently, Alexander Tessarolo in his publication [9], states that the motor control used to be boring. The manual control of motor using potentiometers or digital key pads had jaded the working personal which opens the doors for remote controlling of the drives [10]. Various researchers have published their work based on the remote control of induction motor drives using internet of things (IoT) [11]-[16]. This paper introduces an indigenously developed three-phase two-level inverter with its gate driver circuit which is operated remotely using IoT. This work could find the applicability in the Electric and Hybrid Electric Vehicles.

Rest of the paper is divided into three parts. Second section briefs the developed drive system. Later, the hardware prototype development and its working along with the hardware results are presented in the third section followed by the conclusions in the last section.

\section{Methodology}

The proposed system shown in Fig. 1, consists of a DC source, three-phase two-level H-bridge inverter, threephase star connected squirrel cage induction motor load, controller with Wi-Fi connectivity and the driver circuit required to operate three-phase inverter. All the blocks mentioned here are discussed briefly in the following sub sections.

\section{Three-phase H-Bridge Inverter:}

The three-phase inverter used in the proposed system is modeled using switching functions. To model the inverter, switching function $S_{i}$ (where $i$ can be $r, y$ or $b$ ) is considered to be either logic 1 or - 1 which represents turn ON of top device and bottom device respectively. The value of the pole voltage can be $\pm V_{d c} / 2$ based on the $\mathrm{ON}$ or OFF position of the switch. If the top device of phase- $r$ is turned ON, the pole voltage $v_{r o}$ is $+V_{d c} / 2$ and when the bottom device of phase- $r$ is turned ON then the pole voltage $v_{r o}$ is $-V_{d d} / 2$. Then, the pole voltages of all the three poles of the inverter can be written as

$$
v_{r o}=S_{r} \frac{V_{d c}}{2} ; v_{y o}=S_{y} \frac{V_{d c}}{2} ; v_{b o}=S_{b} \frac{V_{d c}}{2}
$$

The motor phase voltage $v_{r n}$ can be derived as 


$$
v_{r n}=\frac{V_{d c}}{2}\left[\frac{2}{3}\left(S_{r}\right)-\frac{1}{3}\left(\left(S_{y}\right)+\left(S_{b}\right)\right)\right]
$$

Similarly the other phase voltages $v_{y n}, v_{b n}$ of the three-phase inverter output can be derived.

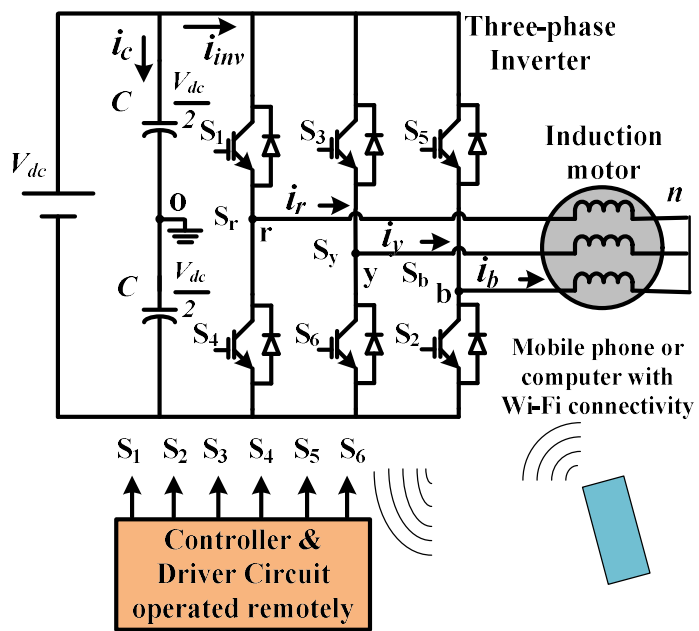

Fig 1: Schematic Circuit Diagram of the Three-phase Inverter fed Induction Motor Drive.

\section{Three-phase Induction Motor Load:}

For modeling and analysis the decoupled form of the three-phase induction motor is considered. For transforming the stator parameters (consider $\phi=\theta$ for stator) and the rotor parameters (consider $\phi=\beta$ for stator) to decoupled form, the matrix for transformation used is given below.

$$
\left[\begin{array}{l}
x_{q m} \\
x_{d m} \\
x_{0 m}
\end{array}\right]=\frac{2}{3}\left[\begin{array}{ccc}
\cos \phi & \cos \left(\phi-\frac{2 \pi}{3}\right) & \cos \left(\phi+\frac{2 \pi}{3}\right) \\
\sin \phi & \sin \left(\phi-\frac{2 \pi}{3}\right) & \sin \left(\phi+\frac{2 \pi}{3}\right) \\
\frac{1}{2} & \frac{1}{2} & \frac{1}{2}
\end{array}\right]\left[\begin{array}{l}
x_{r n} \\
x_{y n} \\
x_{b n}
\end{array}\right]
$$

where, $\theta$ is the angle between the stator $r$-axis and the quadrature $(q)$ axis, $\beta$ is the angle between rotor $r$-axis and the $q$-axis, also $\beta=\theta-\theta_{r}, \theta_{r}$ is the angle between rotor $r$-axis and stator $r$-axis, parameter $x$ can be either voltage ' $v$ ' or current ' $i$ ' or flux linkage ' $\lambda$ ' and subscript parameter $m$ can denote either stator parameters ' $s t$ ' or the rotor parameters ' $r t$ '. The expression for the electromagnetic torque $T_{e m}$ is given by

$$
T_{e m}=\frac{3}{2} \frac{P}{2} L_{m}\left[i_{q s t} i_{d r t}^{\prime}-i_{d s t} i_{q r t}^{\prime}\right]
$$

where, $P$ is the number of poles.

\section{Controller:}

The most important part of an electrical drive system is its controller, which could be termed as the heart of the system. The selection of the controller should be very wise and is based on various parameters. For example, the controller must support pulse width modulation (PWM) signals, the minimum number of PWM pins should be equal to the number of phases or legs of the inverter to be operated. Also, the controller should contain analog to digital converter (ADC) pins if required to operate the drive in closed-loop mode. However, the work presented in this paper is limited to open-loop control.

The other requirement of the controller for the proposed work is the ability to handle either Bluetooth or Wi-Fi connectivity. Hence, ESP32 is the controller considered in the proposed work, which could handle PWM signals, Wi-Fi connectivity and contains ADC pins for future use. In addition, ESP32 holds ultra-low power consumption through power saving features including fine resolution clock gating, multiple power modes, and dynamic power scaling. It is highly integrated with built-in antenna switches, power amplifier, low noise receive amplifier, filters and power management module.

\section{Driver Circuit:}

The major contribution of the paper is the driver circuit, which is indigenously designed and fabricated. The firing pulses generated by the controller cannot be applied directly to the considered power semiconductor devices. Since, the controller generates signals with the magnitude of $3.3 \mathrm{~V}$, whereas the power semiconductor devices (say MOSFET or IGBT) require 12 to $15 \mathrm{~V}$ to get it turned ON. Another issue with the controller directly connecting to the inverter devices is the non-isolation. The controller signals are at very low power level, whereas the inverter devices are operated at high voltages and currents. Hence, the low power controller 
should be isolated with the high power operated inverter devices. The block diagram of the proposed driver circuit is shown in Fig. 2.

The Driver circuit consists of various components such as logical gates AND \& NOT, Opto-isolators. The AND gate is used as buffer to the signals from the controller, where both the inputs of the AND gate are shorted and connected to the controller PWM pin. The logical power supply required to operate the AND gate is $5 \mathrm{~V}$ and is generated using a regulator IC. This boost up the voltage of the PWM signals from $3.3 \mathrm{~V}$ to $5 \mathrm{~V}$. The controller is capable of generating six PWM pulses required for the three-phase inverter, however, only three PWM signals are generated by the controller and the complementary pulses are derived using NOT gate as shown in Fig. 2. So, the controller generated three firing pulses for the top three devices and the complementary firing pulses from the NOT gates are passed through the six opto-isolators. This stage is so important since, this stage of the driver circuit isolates the low power and high power signals. All the six opto-isolators should be powered separately using six isolated logic power supplies. However, this could be reduced to 4 power supplies, because, all the three bottom devices are connected together.

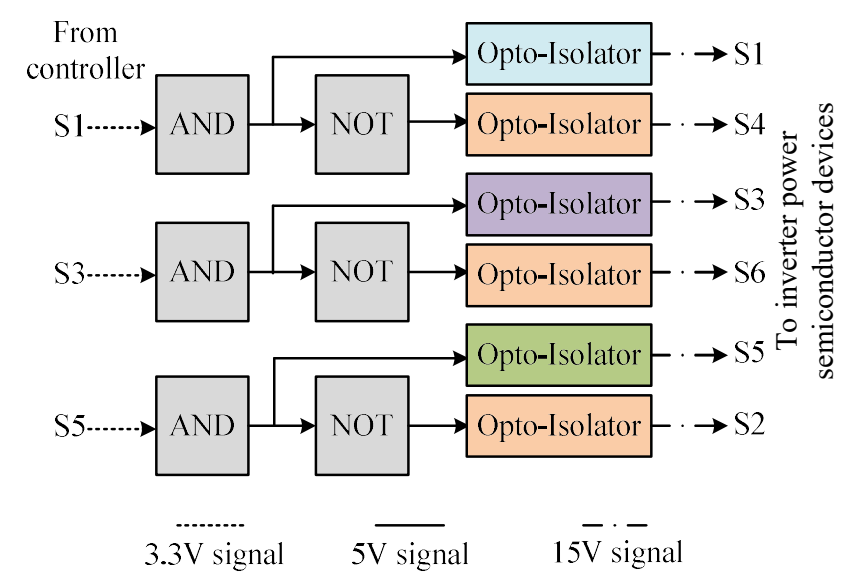

Fig 2: Block Diagram Representation of the Driver Circuit.

\section{Implementation and Results Discussion}

The system shown in Fig. 1 and 2 containing the three-phase inverter and its driver circuit are developed indigenously in the laboratory. The photograph of the developed hardware setup is shown Fig. 3. The hardware shown in Fig. 3 consists of a three-phase inverter using IGBT devices, DC bus capacitors of $1000 \mu \mathrm{F} / 400 \mathrm{~V}$, driver circuit board consisting of the components shown in Fig. 2, logic isolated power supplies for the driver circuit, controller ESP-32, three-phase induction motor load.

The controller is programmed for sine triangle PWM technique wherein the reference and carrier signals are generated as shown in Fig. 4. In this PWM, reference signal is taken to be sinusoidal, with the following constraints- 1 . The peak amplitude of the reference signal should be less than or equal to that of the carrier signal. 2. The frequency of the reference signal defines the frequency of the inverter output voltage and is several orders less than the frequency of the carrier signal. A typical value can be $50 \mathrm{~Hz}$ for the reference sinusoidal signal and $1 \mathrm{kHz}$ for the carrier triangular signal.

Depending on whether the reference signal is larger or smaller than the carrier waveform, either the positive or negative DC voltage is appeared at the output. Over the period of one triangular signal, the average voltage appeared at the load is proportional to the amplitude of the reference signal during this time period. This results in chopped square waveform whose moving average is sinusoidal in nature as shown in Fig. 4.

The reference signal is a sinusoidal waveform of amplitude $V_{m}$, and the amplitude of carrier waveform is $V_{c}$, then the ratio $m_{i}=V_{m} / V_{c}$ is known as modulation index. The modulation index and the DC bus voltage are responsible to define the output voltage magnitude as well as the frequency, which results in the open-loop $V / f$ control.

The hardware setup shown in Fig. 3 is supplied by a programmable DC power supply with the voltage set to $100 \mathrm{~V}$ and the source current is limited to $2 \mathrm{~A}$. The results are captured using a digital storage oscilloscope and are shown in Fig. 5. Fig. 5 shows one of the pole voltages, phase voltages and the phase currents of the threephase inverter connected to the induction motor. Fig. 5 depicts the working of the indigenously built inverter and the driver circuit. In addition, the speed of the induction motor is controlled through IoT cloud wherein the controller and the drive are placed remotely. 


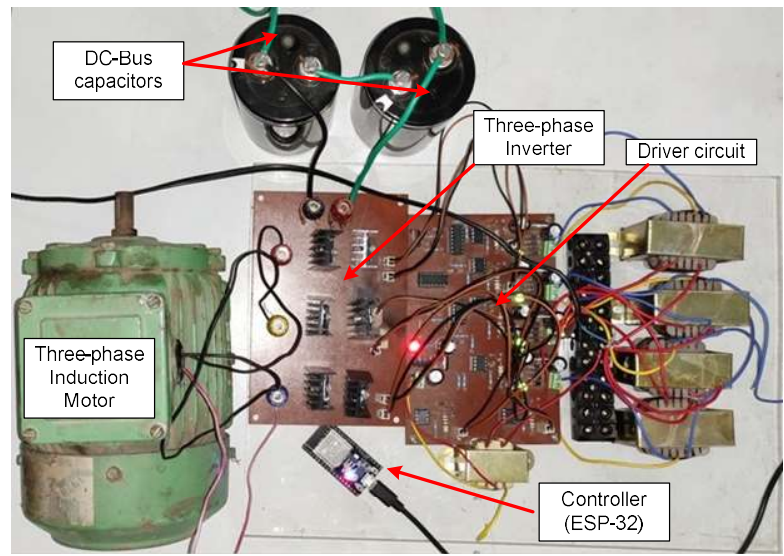

Fig 3: Photograph of the Hardware Setup.

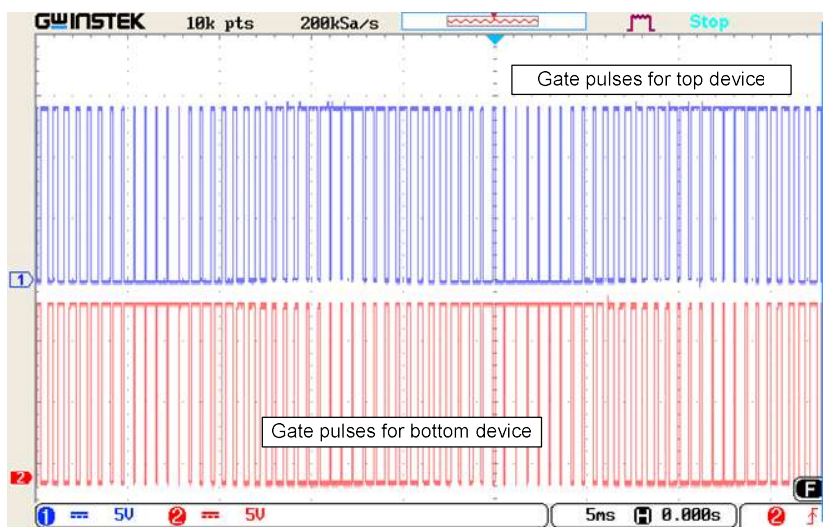

Fig 4: Gate Pulses for Power Electronic Devices Captured from the Driver Circuit.

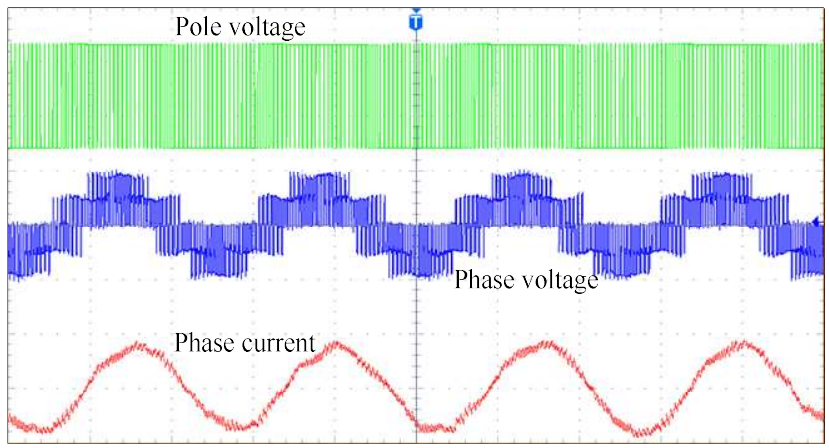

Fig 5: Experimental Results of Pole Voltage (Top), Phase Voltage (Middle) and the Phase Current of Three-phase Inverter Connected to the Induction Motor.

\section{Conclusions}

The three-phase inverter designed and developed indigenously in the laboratory is presented in this paper. The details of all the components used in the electric drive system are briefed. Also, the pulse width modulation technique used to program the controller and to operate the inverter switches is discussed in detail. The working of developed inverter using the controller and driver circuit is demonstrated with the help of hardware results. The speed of the induction motor can be varied using either the mobile phone or the computing system through the Internet of Things. Hence, this system could be used in the applications where the manual entry is restricted and the length of communication cables is a constraint. 


\section{References}

1. R. Karampuri, S. Jain and V. T. Somasekhar, "Common-Mode Current Elimination PWM Strategy along with Current Ripple Reduction for Open-Winding Five-Phase Induction Motor Drive," in IEEE Transactions on Power Electronics, vol. 34, no. 7, pp. 6659-6668, 2019.

2. Liuchen Chang, "Development of a driver board power supply for high power IGBTs used in three-phase inverters," in IEEE Aerospace and Electronic Systems Magazine, vol. 11, no. 8, pp. 24-28, Aug. 1996.

3. K. Ishikawa, K. Suda, M. Sasaki and H. Miyazaki, "A 600V driver IC with new short protection in hybrid electric vehicle IGBT inverter system," Proceedings. ISPSD '05. The 17th International Symposium on Power Semiconductor Devices and ICs, 2005., Santa Barbara, CA, 2005, pp. 59-62.

4. A. B. Shitole, H. M. Suryawanshi, G. G. Talapur and A. A. Chanekar, "A gate driver circuit design for SiC MOSFET based three level NPC inverter with reduced high frequency switching noise," 2017 National Power Electronics Conference (NPEC), Pune, 2017, pp. 185-190.

5. Lan Wu, Ningmei Yu and Yaohui Zhang, "A Programmable Modulator-Driver Circuit," 2008 3rd IEEE Conference on Industrial Electronics and Applications, Singapore, 2008, pp. 2321-2324.

6. N. Sakurai and K. Yahata, "Gate driver integrated circuit for high-current and high-speed insulated-gate bipolar transistors used in hybrid electric vehicle and electric vehicle inverters," 2017 IEEE 3rd International Future Energy Electronics Conference and ECCE Asia (IFEEC 2017 - ECCE Asia), Kaohsiung, 2017, pp. 947952.

7. N. K. Trung and K. Akatsu, "Driver design for 3kW $13.56 \mathrm{MHz}$ multiphase resonant inverter," 2017 IEEE 3rd International Future Energy Electronics Conference and ECCE Asia (IFEEC 2017 - ECCE Asia), Kaohsiung, 2017, pp. 170-174.

8. F. J. C. Padilha, W. I. Suemitsu, M. D. Bellar and P. M. Lourenco, "Low-Cost Gate Drive Circuit for ThreeLevel Neutral-Point-Clamped Voltage-Source Inverter," in IEEE Transactions on Industrial Electronics, vol. 56, no. 4, pp. 1196-1204, April 2009.

9. Alexander Tessarolo, "Motor Control Used To Be Boring", 2016 IEEE Symposium on VLSI Circuits, June 15-17, 2016.

10. S. Potturi and R. P. Mandi, "Critical Survey on IoT Based Monitoring and Control of Induction Motor," 2018 IEEE Student Conf. on Research and Development (SCOReD), Selangor, Malaysia, 2018, pp. 1-6.

11. D. Shyamala, D. Swathi, J. L. Prasanna and A. Ajitha, "IoT platform for condition monitoring of industrial motors," 2017 2nd International Conference on Communication and Electronics Systems (ICCES), Coimbatore, 2017, pp. 260-265.

12. G. Pavithra and V. V. Rao, "Remote Monitoring and Control of VFD fed Three Phase Induction Motor with PLC and LabVIEW software," 2018 2nd International Conference on I-SMAC (IoT in Social, Mobile, Analytics and Cloud) (I-SMAC)I-SMAC (IoT in Social, Mobile, Analytics and Cloud) (I-SMAC), 2018 2nd International Conference on, Palladam, India, 2018, pp. 329-335.

13. W. Tsai, Y. Shih and T. Tsai, "IoT-type Electric Fan: Remote-Controlled by Smart-Phone," 2016 Third International Conference on Computing Measurement Control and Sensor Network (CMCSN), Matsue, 2016, pp. $12-15$.

14. A. C. Thombre, S. Shah, A. S. Thombre, G. T. Haldankar and P. V. Kasambe, "Design of IoT based intelligent AC drive system using space vector algorithm," 2017 International Conference on Communication and Signal Processing (ICCSP), Chennai, 2017, pp. 2097-2100.

15. A. P. Stamelos, A. Papoutsidakis, V. Vikentios, S. A. Papazis and M. G. Ioannides, "Experimental Educational System of AC Electric Drives with Internet of Things," 2018 XIII International Conference on Electrical Machines (ICEM), Alexandroupoli, 2018, pp. 1497-1502.

16. A. Kumar, A. A. Bijapur, B. Charitha, K. R. Kulkarni and K. Natarajan, "An IOT based smart inverter," 2016 IEEE International Conference on Recent Trends in Electronics, Information \& Communication Technology (RTEICT), Bangalore, 2016, pp. 1976-1980. 